\title{
Hydrophilic films based on starch and carboxymethyl starch
}

\author{
Katarzyna Wilpiszewska \\ West Pomeranian University of Technology, Szczecin, Faculty of Chemical Technology and Engineering, Polymer Institute, \\ Pułaskiego 10, 70-322 Szczecin, Poland \\ *Corresponding author: e-mail: kwilpi@zut.edu.pl
}

\begin{abstract}
The hydrophilic films based on starch and carboxymethyl starch (CMS) were obtained using cast method. The effect of CMS content on the physicochemical properties of prepared films were evaluated. With increasing content of starch derivative the moisture absorption, solubility in water as well as swelling ratio increased. The highest values of mechanical parameters (tensile strength and Young's modulus) were determined for the starch/CMS film containing the lowest CMS amount, i.e. 10 wt.\% (1.1 MPa, $15 \mathrm{MPa}$, respectively). For the same system the lowest moisture absorption, solubility in water as well as swelling ratio were reported. Thus, it could be concluded that for this system the highest crosslinking density has been achieved, what was confirmed by DMTA results. Such a film could potentially find application in food or agricultural industry.
\end{abstract}

Keywords: carboxymethyl starch, hydrophilic films, polysaccharide films, starch.

\section{INTRODUCTION}

Starch is a biorenewable, inexpensive and abundant polymer of significant importance in food, paper and textile industry. Preparing starch films requires using plasticizer (mainly multihydroxylic alcohols, e.g. glycerol) to overcome the brittleness of polysaccharide films ${ }^{1}$. Blending starch with other biopolymer allows to obtain materials with new properties, maintaining the biodegradability. The addition of starch derivative, i.e. carboxymethyl starch (CMS) would allow to prepare novel material with modified hydrophobicity, which could be beneficial for e.g. agricultural purposes. Moreover, biodegradable and edible films are desirable for active food packaging films ${ }^{2}$ as well as a drug carrier in pharmacy ${ }^{3}$. There are known starch-based films with carboxymethyl cellulose $(\mathrm{CMC})^{3,4}$, or carboxymethyl chitosan $(\mathrm{CMCh})^{2,5}$. Blending rice starch with the latter resulted in obtaining films with increased both hydrophilicity and mechanical properties ${ }^{3}$.

Carboxymethyl starch is prepared by the so-called Williamson process consisting in introducing ionic substituents into the structure of starch through reaction with monochloroacetic acid or monochloroacetic acid sodium salt ${ }^{6}$. Unlike unmodified starch - CMS is soluble in cold water, and does not exhibit the tendency to retrogradation (recristallization). Moreover, its good freeze-thaw characteristics indicates stability during storage at low temperature ${ }^{7}$. The properties of carboxymethylated derivative depend greatly on its degree of substitution (DS), which is the average number of hydroxyl groups substituted in recurrent polysaccharide unit.

CMS has been reported as a film forming polymer ${ }^{8}$. Blended with CMC could be used as a carrier for pressure sensitive additives ${ }^{9}$. However, the study on preparing and determining the properties of starch/CMS films has not been reported so far.

In this paper the films based on starch/carboxymethyl starch polymers (using glycerol and citric acid as plasticizer and crosslinking agent, respectively) have been prepared. Citric acid (CA), an organic acid widely existing in citrus fruits, was applied as containing three carboxyl and one hydroxyl group could interact with $\mathrm{OH}$ and carboxymethyl groups of starch and CMS, respectively.
Moreover, formed bonds could prevent starch from recrystallization and retrogradation ${ }^{4}$. The effect of high substituted CMS content (DS 0.8) on the physicochemical properties (solubility in water, swelling ratio, moisture absorption, as well as thermal and mechanical properties) of prepared film has been determined.

\section{EXPERIMENTAL}

\begin{abstract}
Materials
Potato starch was purchased from Nowamyl S.A. Nowogard (Poland). Monochloroacetic acid (MCA, a.g.; Chempur, Poland) was used as an etherifying agent, whereas isopropanol (pure; Chempur) was used as a reaction medium. Sodium hydroxide (microgranules), acetic acid, and copper sulfate penthahydrate were the products of Chempur, murexide and ethylenediaminetetraacetic acid disodium salt dehydrate (EDTA) of Sigma-Aldrich (Germany). Glycerol (technical pure) and citric acid monohydrate (CA, analytically pure) were purchased from Chempur (Poland).
\end{abstract}

\section{Preparation of CMS with high degree of substitution}

Modification of potato starch was carried out in a batch reactor equipped with a mechanical stirrer, a thermocouple, and a capillary tube supplying nitrogen to the reaction system. Starch (13.6-14 wt.\% moisture) was etherified in isopropanol/water in a one-step process. In the batch reactor, MCA was dissolved in isopropanol, and then aqueous solution of $\mathrm{NaOH}$ was added (the molar ratio of MCA/polysaccharide recurrent unit was 2, whereas $\mathrm{NaOH} / \mathrm{MCA} 2.2$ ). When the mixture became white and homogeneous, starch and remaining $\mathrm{NaOH}$ were introduced. Obtained product was filtered, neutralized with glacial acetic acid, washed five times in 80 wt.\% methanol aqueous solution, and then washed once again in methanol and dried in the air.

\section{METHODS}

\section{Determining the degree of substitution}

Degree of substitution was determined according to the method described in other work ${ }^{\mathbf{1 0}}$. The CMS sample was 
moisturized by $1 \mathrm{~mL}$ of ethanol and dissolved in $50 \mathrm{~mL}$ of distilled water. Subsequently, buffer was added $\left(\mathrm{NH}_{4} \mathrm{Cl}\right.$ aqueous solution, $20 \mathrm{~mL}$ ), neutral $\mathrm{pH}$ was adjusted, and then the whole mixture was poured into a measuring flask $(250 \mathrm{~mL})$ with $50 \mathrm{~mL} \mathrm{CuSO}_{4}$ solution. After 15 min, the measuring flask was filled up with water and the whole content was filtered. Filtrate was titrated with EDTA solution using murexide as an indicator.

\section{Preparation of S/CMS films}

Into $50 \mathrm{~mL}$ of distilled water $0.5 \mathrm{~g}$ potato starch $(\mathrm{S})$, glycerol and citric acid was added and heated for 30 min at $90^{\circ} \mathrm{C}$ while stirring. After cooling, $50 \mathrm{~mL}$ of CMS (DS 0.8 ) solution was added to give 10, 30, 50, 70 or 90 wt.\% CMS (basing on dry polysaccharide mixture) in the final system. In the films symbols: S/CMS_10 the number is the percentage of CMS in the $\mathrm{S} / \mathrm{CM} C$ dry mixture. Subsequently, the mixture was mixed gently (to remove air bubbles) to homogenization and poured into PTFE mold and dried for 48 hours at $60^{\circ} \mathrm{C}$. Obtained film (thickness 200-300 mm) was peeled off and used for further tests.

\section{Fourier transform infrared spectroscopy (FTIR)}

The FTIR analyses of the films were performed in Nexus FTIR Spectrometer Thermo Nicolet with Golden Gate ATR attachment. The resulting spectra were converted using the software OMNIC. Before measurement, starch film was immersed in distilled water for $24 \mathrm{~h}$ at room temperature to remove residual $\mathrm{CA}$ and dried at $50^{\circ} \mathrm{C}^{\mathbf{1 1}}$.

\section{Moisture absorption}

For each film three squares $(1.5 \mathrm{~cm} \mathrm{x} 1.5 \mathrm{~cm})$ were prepared and placed for two weeks in desiccator to dry. Dry samples were weighted and subsequently transferred to a climatic chamber $\left(55 \pm 2 \%\right.$ humidity, $\left.25 \pm 2^{\circ} \mathrm{C}\right)$. The weight of tested samples was controlled 3, 5, 7, 24, 48 and 72 hours after placing the samples in a climate chamber. Moisture absorption was calculated using equation ${ }^{\mathbf{1 2}}$ :

$A_{t}=\frac{M_{t}-M_{0}}{M_{0}} \cdot 100 \%$

where: $\mathrm{A}_{\mathrm{t}}-$ moisture absorption after time $\mathrm{t}[\%] ; \mathrm{M}_{0}-$ mass of dry sample $[\mathrm{g}] ; \mathbf{M}_{\mathrm{t}}$ - mass of sample after time t: $3,5,7,24,48$ and 72 , respectively [g].

\section{Swelling ratio}

The swelling ratio was determined according to the method reported by Suriyatem et al. ${ }^{5}$ with slight modifications. For each film three squares $(1.5 \mathrm{~cm} \mathrm{x} 1.5 \mathrm{~cm})$ were prepared and placed for two weeks in desiccator to dry. Dry samples were weighed $\left(M_{1}\right)$ and subsequently transferred to test tubes filled with $50 \mathrm{~mL}$ distilled water. After $24 \mathrm{~h}$ immersion the samples were removed from the water, wiped with absorbing paper from the excess water on the film surface and weighted $\left(\mathrm{M}_{2}\right)$. The swelling ratio was calculated using equation:

Swelling ratio $=\frac{M_{2}-M_{1}}{M_{1}} \cdot 100 \%$

\section{Solubility in water}

For each film three squares $(1.5 \mathrm{~cm} \times 1.5 \mathrm{~cm})$ were prepared and placed for two weeks in desiccator to dry. Dry samples were weighed and subsequently transferred to test tubes filled with $50 \mathrm{~mL}$ distilled water. After $24 \mathrm{~h}$ immersion in water samples were dried for $24 \mathrm{~h}$ at $60^{\circ} \mathrm{C}$ and weighed. Solubility was calculated using equation ${ }^{\mathbf{1 2}}$ :

$T S M=\frac{M_{1}-M_{2}}{M_{1}} \cdot 100 \%$

where: TSM - Total Soluble Mater (in water) [\%]; $\mathrm{M}_{1}$ - beginning mass of dry sample $[\mathrm{g}] ; \mathbf{M}_{2}$ - mass of dry sample after solubility test [g].

\section{Mechanical properties}

The mechanical properties of S/CMS films were determined using a tensile tester (Instron 4026, Instron Corporation) equipped with $1 \mathrm{kN}$ load cell. The specimens (10 mm x $100 \mathrm{~mm}$ strips) were conditioned at $\mathrm{RH}=$ $55 \%$ for $24 \mathrm{~h}$. The initial grip separation and cross-head speed were $50 \mathrm{~mm}$ and $1 \mathrm{~mm} / \mathrm{min}$, respectively. The true strain e was determined by $\varepsilon=\ln \left(\mathrm{L} / \mathrm{L}_{0}\right)$, where $\mathrm{L}$ and $\mathrm{L}_{0}$ were the length during the test and the length at zero time, respectively. The true stress $\sigma$ was calculated by $\sigma=\mathrm{F} / \mathrm{S}$, where $\mathrm{F}$ was the applied load and S the cross-section area. As $\mathrm{S}$ was determined assuming that the total volume remained constant, so $\mathrm{S}=\mathrm{S}_{0} \mathrm{~L}_{0} / \mathrm{L}$, where $\mathrm{S}_{0}$ was the initial cross-sectional area. The stress-strain curves were plotted and the tensile strength as well as Young modulus were determined from the slope of the strain region in the vicinity of $\sigma=\varepsilon=0$ ([d $\sigma / \mathrm{d} \varepsilon]$ $\left.{ }_{\varepsilon \rightarrow 0}\right)^{\mathbf{1 3}}$. The mechanical tensile data were averaged over ten specimens.

\section{Dynamic mechanical thermal analysis (DMTA)}

The DMTA analyses of the CMS films were determined using DMTA Q800 (TA Instruments). Measurements were performed using powder testing adaptor, at heating rate of $3^{\circ} \mathrm{C} / \mathrm{min}$ from -70 to $170^{\circ} \mathrm{C}$, frequency $1 \mathrm{~Hz}$.

\section{RESULTS AND DISCUSSION}

\section{Fourier transform infrared spectroscopy (FTIR)}

In Fig. 1 the FTIR spectra of citric acid, carboxymethyl starch, native starch, and CMS-based film were presented (for the sake of clarity the spectra of one film only was shown). The S/CMS film was washed to remove residual citric acid before testing ${ }^{11}$.

In case of native starch and CMS the absorption band between $3600-3000 \mathrm{~cm}^{-1}$ and at $2900 \mathrm{~cm}^{-1}$ could be attributed to hydroxyl groups and to $\mathrm{CH}_{2}$ stretching vibrations, respectively ${ }^{14}$. The special pattern, typical for native starch, in the region of $970 \mathrm{~cm}^{-1}$ and $1200 \mathrm{~cm}^{-1}$ is preserved in CMS as well as S/CMS samples. Protonated carboxylic groups (CA) give a C-O band at about 1700 $\mathrm{cm}^{-1}$. The unmodified CMS carboxylate (-COO-) gives strong absorption band at about $1600 \mathrm{~cm}^{-1}$ (intensity of this band strongly relates to high DS value), 1440 and $1325 \mathrm{~cm}^{-1} 15$. For S/CMS film the absorption band of carbonyl group was observed at $1715 \mathrm{~cm}^{-1}$ which is the confirmation of chemical linkages between starch and citric acid (crosslinking agent) via ester bonds. 


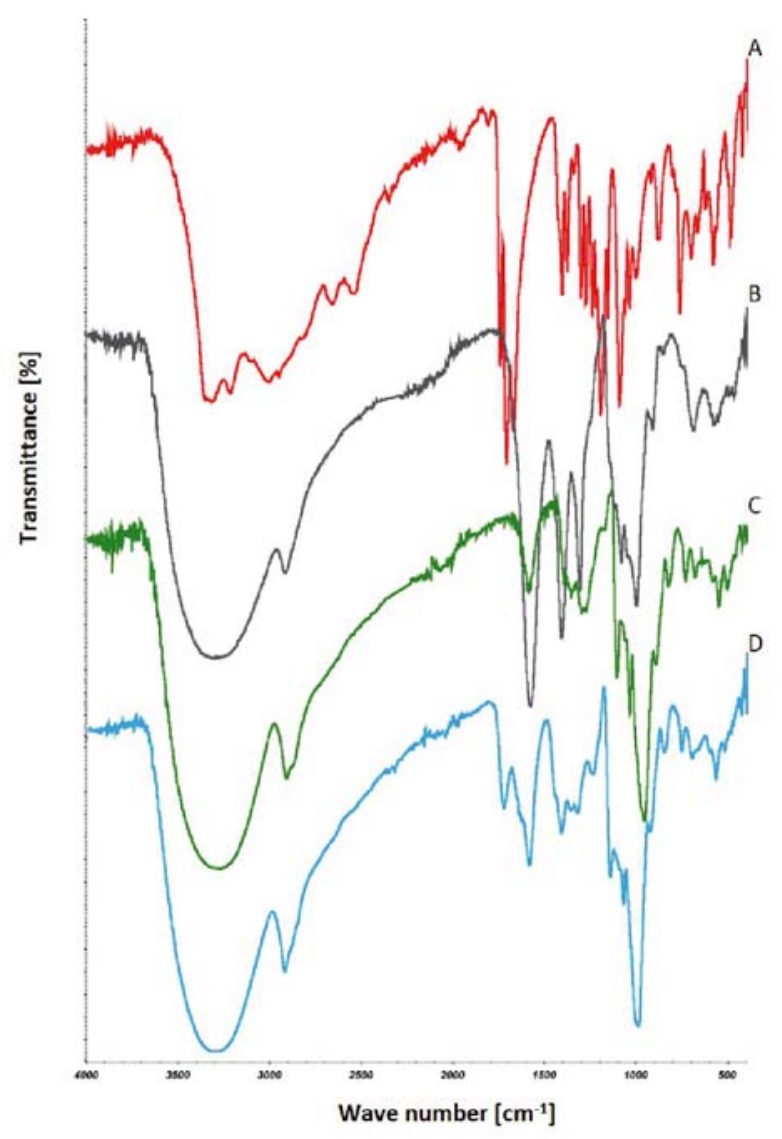

Figure 1. FTIR spectra of CA (A), CMS (B), native starch (C), and S/CMS_50 film (D)

\section{Moisture absorption}

In Fig. 2 the moisture absorption of polysaccharide-based films containing various CMS amount was presented. During storage at RH 55\% the water absorption gradually increased and even after $120 \mathrm{~h}$ (5 days) tended to gain moisture (only the system with the lowest CMS content tended to balance after ca. $48 \mathrm{~h}$ ). Generally, the higher carboxymethyl derivative content the higher moisture absorption noted (up to ca. $18 \%$ after $120 \mathrm{~h}$ for S/CMS_90 system). It is the result of higher hydrophilic character of CMS when compared to starch. An effect of carboxymethyl starch presence in the starch-based films differed substantially from the carboxymethyl cellulose one; the latter exhibited reduced moisture absorption value with $\mathrm{CMC}$ content in the system ${ }^{4}$. Although $\mathrm{CMC}$ is hydrophilic material as well, its hydrophilicity is lower than starch and significantly lower than CMS. Moreover, $\mathrm{CMC}$ partially maintained the fabric form of cellulose,

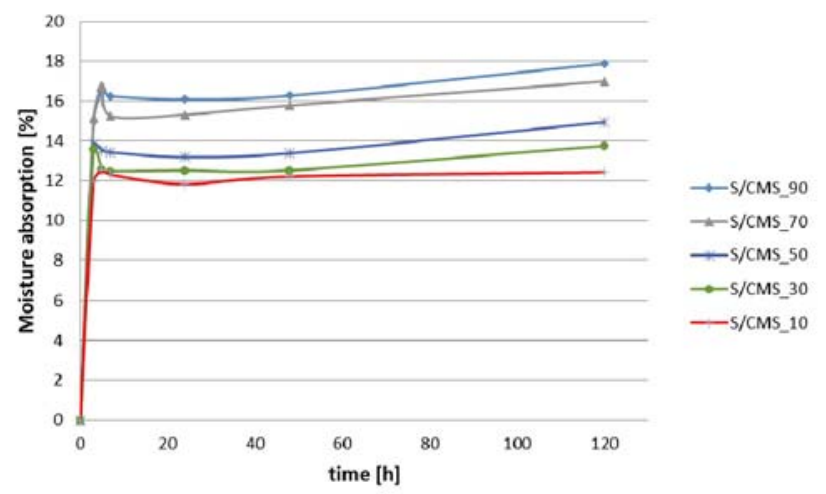

Figure 2. Moisture absorption of S/CMS-based films whereas highly substituted CMS exhibits amorphous character $^{\mathbf{1 6}}$.

\section{Solubility in water and swelling ratio}

The solubility in water and swelling ratio of S/CMS films as a function of CMS content were shown in Fig. 3. The samples maintained their integrity, i.e., they did not dissolve or break apart during the tests. This indirectly indicates successful crosslinking taking account that CMS is soluble in cold water. It is worth to admit that all the samples after measurement visually significantly gained their volume.

Swelling ratio refers to the water retaining capacity and depends on the presence of hydrophilic groups, free
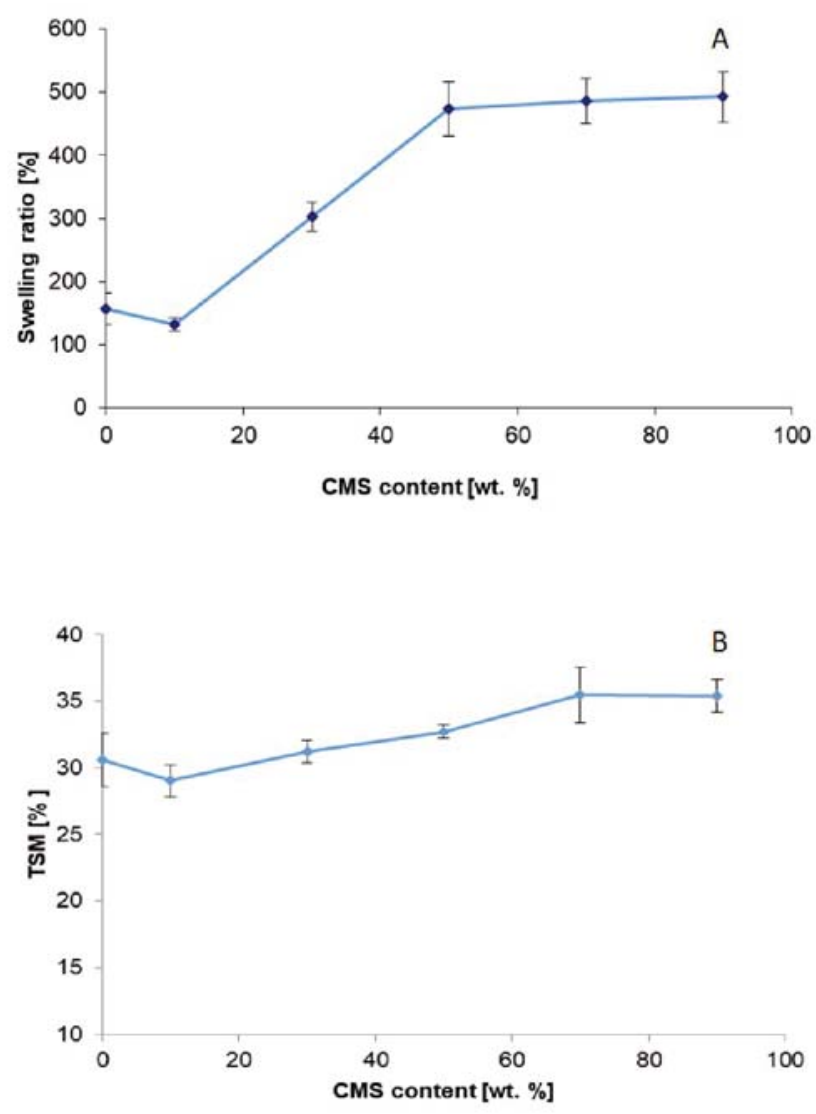

Figure 3. Swelling ratio (A) and solubility (B) in water of S/ CMS films with various starch derivative content

volume as well as crosslinking density ${ }^{5}$. The swelling ratio increased significantly with CMS content up to $50 \mathrm{wt}$. \% (from ca. $180 \%$ to ca. $460 \%$ for starch-based film and this with 50 wt.\% CMS, respectively) - Fig. 3A. In case of the systems with higher CMS content the swelling values were similar, no higher CMS amount effect was noted, revealing that the steric repulsion could result in lower crosslinking efficiency when compared to those with lower CMS addition. Moreover, for the system with the lowest starch derivative amount a slight drop of this parameter was noted. It could suggest that starch derivative was washed out from the system. However, further tests revealed that this system exhibited the lowest solubility in water - Fig. 3B. Thus, it could be concluded that for S/CMS_10 the highest crosslinking density has been achieved.

Generally, with increasing CMS content the films exhibited solubility increase, from ca. $29 \%$ up to ca. $35 \%$ for 
the systems with $10 \%$ and $90 \%$ CMS, respectively. Such an effect was a result of stronger hydrophilic character of starch derivative than native starch, what correlates with the moisture absorption results. Moreover, in case of the systems with higher CMS content the steric repulsion could result in lower crosslinking efficiency when compared to those with lower CMS amount.

For the sorghum starch films with CMC the solubility tendency was completely different, i.e. TSM decreased with CMS content ${ }^{17}$. However, it was related to the fibrous character of CMC creating a winding road effect for the water molecules.

\section{Mechanical properties}

The mechanical properties of S/CMS films were characterized by tensile measurements at room temperature. The dependence of tensile strength, Young's modulus as well as elongation at break on CMS content was presented in Fig. 4. Generally, the Young's modulus (from ca. $14 \mathrm{MPa}$ to ca. $0.4 \mathrm{MPa}$ for $10 \mathrm{wt} . \%$ and $90 \mathrm{wt} . \% \mathrm{CMS}$, respectively) and tensile strength (from ca. 1.1 MPa to $0.2 \mathrm{MPa}$ for $10 \mathrm{wt} . \%$ and $90 \mathrm{wt} . \% \mathrm{CMS}$, respectively) decreased with CMS content in the polysaccharide-based films. However interestingly, the systems containing the lowest CMS content exhibited slightly higher values of these parameters than starch-based film. Similarly, the
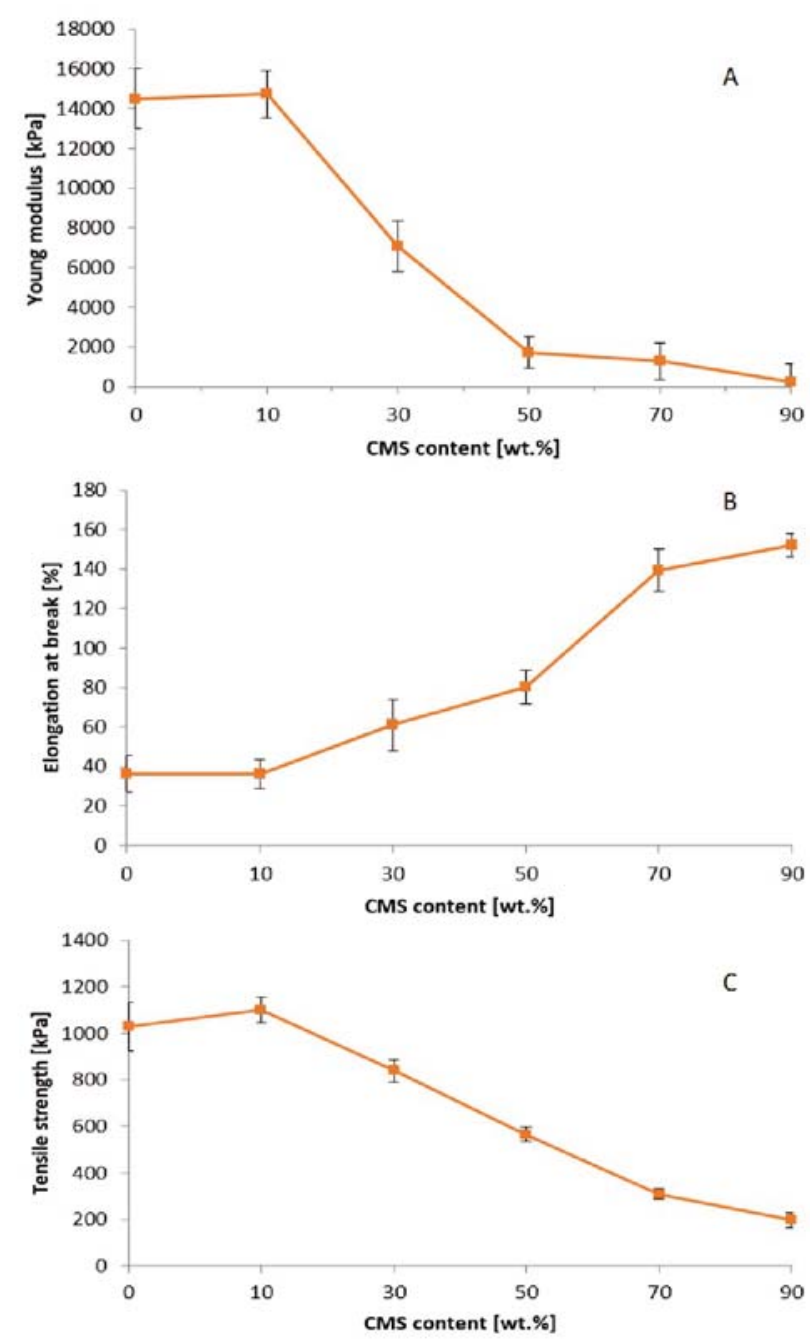

Figure 4. The dependence of CMS content on Young's modulus (A), elongation at break (B) and tensile strength (C) of the S/CMS-based films elongation at break of S/CMS films were higher than for starch-based film, except for the system with $10 \mathrm{wt}$. $\%$ where the value was similar to the system without CMS. That could suggest that for S/CMS_10 the best compatibility between components has been achieved (interpenetrated polymer network). Moreover, is could be noticed that native starch-based films exhibited better mechanical properties than its carboxymethylated derivative-based one, which could be a result of e.g. CMS molecular weight reduction resulting in higher chain mobility ${ }^{18}$ and subsequently leading to elongation at break increase (from ca. 40 to ca. $140 \%$ for the systems containing $10 \mathrm{wt} . \%$ and $90 \mathrm{wt} . \%$ CMS, respectively).

Similar results were reported for corn starch films with CMC from papaya peel where tensile strength decreased from ca. $31 \mathrm{MPa}$ to ca. $14 \mathrm{MPa}$ for starch film only and the system with $25 \% \mathrm{CMC}$ content, respectively ${ }^{19}$. On the other side, Ghanbarzadeh et al. ${ }^{4}$ reported that the addition of carboxymethyl cellulose into starch matrix resulted in increase of tensile strength, however the CMC chains were longer than starch (as well as CMS), hence exhibited higher tensile strength than starch matrix ${ }^{3}$.

For rice starch films with carboxymethyl chitosan the mechanical properties strongly depended on $\mathrm{CMSCh}$ content. For the system containing up to ca. $30 \%$ w/w $\mathrm{CMSCh}$ the tensile strength value was similar to starch based film. Introducing higher amount of carboxymethylated derivative resulted in noticeable increase of tensile strength ${ }^{5}$.

\section{Dynamic mechanical thermal analysis (DMTA)}

The evaluation of the loss factor (tan d) as a function of temperature for S/CMS films was shown in Fig. 5. The loss factor is sensitive to molecular motion and its peak relates to the glass transition temperature ${ }^{8}$. All the curves of S/CMS systems revealed two transitions indicating phase separation. Generally, with CMS content increase the temperature values of both transitions shifted toward lower values, however significant drop was noted for the systems with 50 wt.\% and more CMS - Tab. 1. For S/ CMS_10 system the phase separation was not so clear as for the other ones, suggesting the best homogeneity. The decrease of $T_{g}$ with CMS content increase could be the result of lower crosslinking density, as with higher CMS amount steric repulsion interactions gain intensity, as well as higher movability of the molecules ${ }^{\mathbf{2 0}}$.

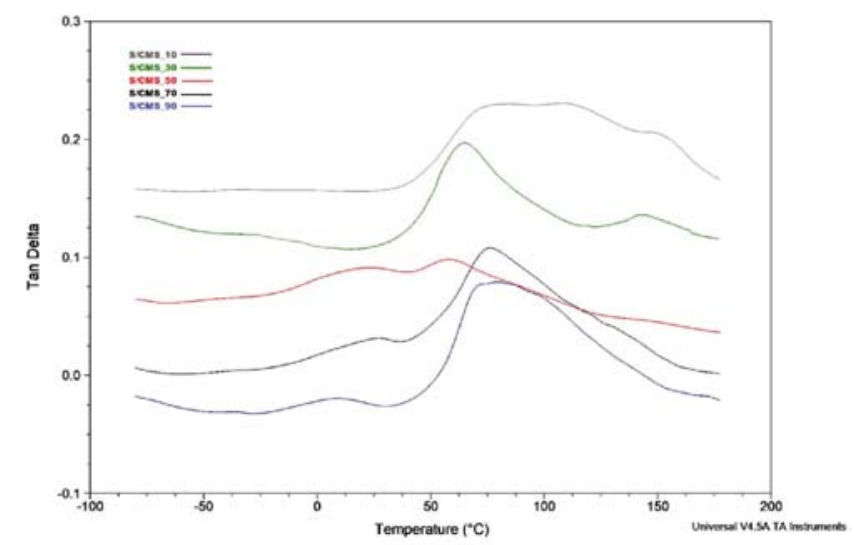

Figure 5. The DMTA curves of S/CMS films 
Table 1. The transition temperatures (DMTA, $\tan \sigma$ ) of S/CMS films

\begin{tabular}{|l|c|c|}
\hline Film symbol & $\mathrm{T}_{\beta}\left({ }^{\circ} \mathrm{C}\right)$ & $\mathrm{T}_{\alpha}\left({ }^{\circ} \mathrm{C}\right)$ \\
\hline S/CMS_10 & 108.4 & 153.9 \\
\hline S/CMS_30 & 65.4 & 142.5 \\
\hline S/CMS_50 & 19.7 & 58.5 \\
\hline S/CMS_70 & 24.2 & 79.7 \\
\hline S/CMS_90 & 7.2 & 79.6 \\
\hline
\end{tabular}

For S/CMS 10 system the highest $T_{a}$ and $T_{b}$ values (ca. $154^{\circ} \mathrm{C}$ and $109^{\circ} \mathrm{C}$, respectively) have been noted, revealing the most efficient crosslinking. These results correlate to the results of moisture sorption, swelling in water as well as mechanical properties tests results indicating that the CMS content in starch-based films should not extent $10 \mathrm{wt} . \%$.

\section{CONCLUSIONS}

The hydrophilic films based on starch and carboxymethyl starch were obtained using cast method. The FTIR spectra revealed that crosslinking via ester bridges with citric acid occurred. The effect of CMS content on physicochemical properties of prepared films were evaluated. With increasing the starch derivative content the moisture absorption increased up to $18 \%$, and even after $120 \mathrm{~h}$ (5 days) the systems with more than $10 \mathrm{wt} . \%$ CMS continued to absorb moisture. The solubility in water as well as swelling ratio importantly depended on CMS content, and generally, the value of both parameters increased with CMS amount in the system. The lowest values were noted for S/CMS_10 (ca. 28\% and $125 \%$, respectively), the highest for S/CMS_90 (ca. 35\% and $480 \%$, respectively). The mechanical tests revealed that with CMS amount in the system the highest tensile strength and Young's modulus decreased (to ca. 0.2 $\mathrm{MPa}$ and ca. 0.4 MPa, respectively for S/CMS 90) whereas elongation at break increased (up to ca. $160 \%$, for the same film). Interestingly, the highest values of mechanical parameters (tensile strength and Young's modulus) were determined for S/CMS 10 film (ca. 1.1 MPa, ca. $15 \mathrm{MPa}$, respectively). Thus, it could be suggested that the system with the lowest CMS content exhibited the highest crosslinking density, what was confirmed by the DMTA results. Moreover, the highest homogeneity of this system has been determined as well as significantly higher values of transition temperatures (ca. $108^{\circ} \mathrm{C}$ and ca. $\left.154^{\circ} \mathrm{C}\right)$.

Bearing that in mind, it could be concluded that the hydrophilic starch-based films containing $10 \mathrm{wt} . \% \mathrm{CMS}$ exhibited the most promising physicochemical properties and potentially could find application in food or agricultural industry.

\section{LITERATURE CITED}

1. Wilpiszewska, K. \& Spychaj, T. (2006). Heat plasticization of starch by extrusion in the presence of plasticizers. Polimery 51, 325-404. DOI: not given.

2. Suriyatem, R., Auras, R.A., Rachtanapun, C. \& Rachtanapun, P. (2018). Biodegradable rice starch/carboxymethyl chitosan films with added propolis extract for potential use as active food packaging. Polymers 10, 954. DOI: 10.3390/ polym10090954.

3. Wahyuningtyas, D. \& Dinata, A. (2018). Combination of carboxymethyl cellulose (CMC) - corn starch edible film and glycerol plasticizer as a delivery system of diclofenac. AIP Conf. Proc. 1977, 030032. DOI: 10.1063/1.5042952.

4. Ghanbarzadeh, B., Almasi, H. \& Entezami, A.A. (2011). Improving the barrier and mechanical properties of corn starch-based edible films: Effect of citric acid and carboxymethyl cellulose. Ind. Crop. Prod. 33, 229-235. DOI: 10.1016/j. indcrop.2010.10.10.016.

5. Suriyatem, R., Auras, R.A. \& Rachtanapun, P. (2018). Improvement of mechanical properties and thermal stability of biodegradable rice starch-based films blended with carboxymethyl chitosan. Ind. Crop. Prod. 122, 37-48. DOI: 10.1016/j. indcrop.2018.05.047.

6. Yanli, W., Wenyuan, G. \& Xia, L. (2009). Carboxymethyl Chinese yam starch: Synthesis, characterization, and influence of reaction parameters. Carbohyd. Res. 344, 1764-1769. DOI: 10.1016/j.carres.2009.06.014.

7. Noor Fadzlina, Z.A., Karim, A.A. \& Teng, T.T. (2005). Physicochemical properties of carboxy-methylated sago (metroxylon sagu) starch. J. Food Sci. 70, 560-567. DOI: 10.1111/j.13652005.tb08305.x.

8. Wilpiszewska, K., Antosik, A.K. \& Spychaj, T. (2015). Novel hydrophilic carboxymethyl starch/montmorillonite nanocomposite films. Carbohyd. Polym. 128, 85-89. DOI: 10.1016/j. carbpol.2015.04.023.

9. Antosik, A.K., Wilpiszewska, K. \& Czech, Z. (2017). Carboxymethylated polysaccharide-based films as carriers for acrylic pressure-sensitive adhesives. Int. J. Adhes. Adhes. 73, 75-79. DOI: 10.1016/j.ijadhadh.2016.11.011.

10. Kessel, H. (1985). Determination of the functional group and the degree of substitution of carboxymethyl starch. Starch 37, 334-336. DOI: 10.1002/star.19850371005.

11. Reddy, N. \& Yang, Y. (2010). Citric acid cross-linking of starch films. Food Chem. 118, 702-711. DOI: 10.1016/j. foodchem.2009.05.050.

12. Almasi, H., Ghanbarzadeh, B. \& Entezami, A.A. (2010). Physicochemical properties of starch-CMC-nanoclay biodegradable films. Int. J. Biol. Macromol. 46, 1-5. DOI: 10.1016/j. ijbiomac.2009.10.001

13. Angles, M.N. \& Dufresne, A. (2000). Plasticized starch/ tunicin whiskers nanocomposites. 1. Structural analysis. Macromol. 33, 8344-8353. DOI: 10.1021/ma0008701.

14. Jiang, Q., Gao, W., Li, X., Liu, Z., Huang, L. \& Xiao, P. (2011). Synthesis and properties of carboxymethyl Pueraria thomsonii Benth. starch. Starch 63, 692-699. DOI: 10.1002/ star.201100047.

15. Spychaj, T., Zdanowicz, M., Kujawa, J. \& Schmidt, B. (2013). Carboxymethyl starch with high degree of substitution: synthesis, properties and application. Polimery 58, 501-509. DOI: 10.14314/polimery.2013.503.

16. Spychaj, T., Wilpiszewska, K. \& Zdanowicz, M. (2013). Medium and high substituted carboxymethyl starch: Synthesis, characterization and application. Starch 65, 22-33. DOI: 10.1002/star.201200159.

17. Putri, D.A., Setiawan, A. \& Anggraini, P.D. (2016). Effect of carboxymethyl cellulose (CMC) as biopolymers to edible film sorghum starch hydrophobicity characteristics. AIP Conf. Proc. 1818, 020044. DOI: 10.1063/1.4976908.

18. Azevedo, V.M., Dias, M.V, Borges, S.V., Costa, A.L.R., Silva, E.K., Medeiros, É.A.A. \& Soares, N.F.F. (2015). Development of whey protein isolate bio-nanocomposites: Effect of montmorillonite and citric acid on structural, thermal, morphological and mechanical properties. Food Hydrocolloid. 48, 179-188. DOI: 10.1016/j.foodhyd.2015.02.014.

19. Rachtanapun, P. (2009). Blended films of carboxymethyl cellulose from papaya peel (CMCp) and corn starch. Agr. Nat. Resour. (formerly Kasetsart J. - Nat. Sci.) 43, 259-266. DOI: not given.

20. Menzel, C., Olsson, E., Plivelic, T., Andersson, R., Johansson, C., Kuktaite, R., Järnström, L. \& Koch, K. (2013). Carbohyd. Polym. 96, 270-276. DOI: 10.1016/j.carbpol.2013.03.044. 